\title{
Sex determination using mastoid process
}

\author{
Jigyasa Passey, Suniti R Mishra, Rahul Singh, K Sushobhana, Shailendra Singh, Priyanka Sinha \\ Department of Anatomy, G.S.V.M. Medical College, Kanpur
}

\section{A B S TR A C T}

Objective: Osteometric studies using individual bones have been a topic of interest among researchers. Such researches are a tool for conducting studies related to evolution, demographic profiles and forensic sciences. Skull is important in this regard as it resists adverse environmental conditions over time. The mastoid process can thus be used as a marker of sex as well as ancestry of individuals and populations. The aim of this study was to evaluate the use of mastoid process as a tool for sex determination in unidentified skeleton. Materials and Methods: 70 (44 male and 26 female) complete undamaged skulls of known sex were used for the study. Mastoid length was recorded on the right and left mastoid process in each skull. Measurements were made with a digital vernier caliper. Results: Statistics revealed high significance $(p<0.0001)$ for the mastoid length for sex determination. Conclusion: Reports on the use of mastoid process as a tool for sex estimation in unidentified human skeleton have been reported in different populations. The present study supports this finding among the Indian population.

Key words: Mastoid length, Mastoid process, Sexual dimorphism, Skull, Forensic anthropology

\section{INTRODUCTION}

Study on human skeletal remains for sex determination has been a topic of interest among researchers. Osteometric studies using individual bones exhibiting sexual dimorphism have been reported among different populations. ${ }^{1}$ Human evolutionist study sexual dimorphism to understand the etiology of how Homo sapiens came to have less sexual dimorphic features than our ancestors that is the Cro magnun. Bio archaeologist study sexual dimorphism to recreate the demographic profile of our ancestors.

Sex classification is more precise in pelvic remains than the skull but whole and complete pelvis is not always available for analysis. ${ }^{2}$ Skull is probably the second best region of the skeleton to determine sex. ${ }^{3}$ Achievement of sex determination depends upon the completeness of the skeleton. Often fragmentary remains are available, instead of complete skeletons for forensic evaluation. Furthermore, petrous part of temporal bone is resistant to destruction and damage such as burning. ${ }^{4-5}$ The mastoid region is favorable for sex determination as it is one of the most protected region and resistant to damage due to its anatomical position at the base of the skull. Also, mastoid process is one of the most dimorphic trait, females have smaller mastoid than males. ${ }^{6,7}$ The present study was conducted to validate the mastoid length as a parameter for determination of sex of fragmentary skeletal remains.

\section{MATERIALS AND METHODS}

Seventy adult human skulls (26 females, 44 males) of North Indian origin were used in the study to determine the role of mastoid length as a metric parameter in sexual dimorphism. The sample study was conducted in the Anthropology museum, Department of Anatomy, GSVM Medical College, Kanpur. The skulls, of known sex with no apparent deformity or diseases, were included in the study. Senile and juvenile skulls were excluded from the study. The mastoid dimensions were attained with a digital vernier caliper to the closest millimeter. The mastoid measurements were taken on both sides of the skull and the average was calculated. The average was then contemplated for statistical analysis. All the measurements were taken after 
undertaking biometric training and done by single observer to avoid any inter-observer error.

The length of the mastoid process was calculated from a point on the Frankfurt plane vertically downwards to the tip of mastoid process. ${ }^{7}$ The skull was placed on the right side and was facing the observer, the fixed arm of the Vernier caliper was positioned tangentially on the upper border of the auditory meatus in the Frankfurt plane (Fig. 1) and pointing to the lowest point on the border of the orbit by visual sighting. The calibrated bar lies perpendicular to the Frankfurt plane of the skull. The measuring arm was shifted until it lied at the same level with the tip of the process. The mastoid length was computed from this line to the tip of the mastoid (Fig. 2).

\section{RESULT AND DISCUSSION}

As per our observation, the mean mastoid length in male skulls was $29.7 \mathrm{~mm}$ with Standard Deviation 3.67 and the mean mastoid length in female skulls was $24.5 \mathrm{~mm}$ with Standard deviation 3.57. The calculated P-value was $<0.0001$ which was very significant (Table 1). Statistics shows distinct differentiation between male and female mastoid process. In the 70 skulls computed, the lineal dimension of the mastoid length was higher in males than in females.

Based on the direction of the mastoid process in relation to a vertical plane as assessed visually, the mastoid processes were classified into three main types, viz. M, N and F type (M- male, N- neutral, F- female type). ${ }^{8}$ It was also suggested that when skulls were placed on flat surface, the male skulls rest on the mastoid processes while female skulls on occipital condyles or other portions of the skull. ${ }^{8}$ This observation indirectly indicates that males skulls have more mastoid length as compared to female skulls, that is why, male skulls rest on mastoid processes but not female skulls.

As per studies conducted on Cape population ${ }^{9}$ the mean calculated in males was $29.3 \mathrm{~mm}$ and $26.5 \mathrm{~mm}$ in females. In Caucasian population ${ }^{10}$ the mean mastoid length in male and female skulls was evaluated as $28.06 \mathrm{~mm}$ and $25.21 \mathrm{~mm}$ respectively while in the studies conducted on Negroes ${ }^{10}$ the mean mastoid lengths determined were $30.32 \mathrm{~mm}$ and $26.34 \mathrm{~mm}$ in male and female skulls respectively. In a study

\begin{tabular}{|c|c|c|c|c|c|}
\hline \multirow[t]{2}{*}{ Parameter } & \multicolumn{2}{|c|}{ Male } & \multicolumn{2}{|c|}{ Female } & \multirow[t]{2}{*}{$P$-value } \\
\hline & Mean & $\begin{array}{l}\text { Standard } \\
\text { deviation }\end{array}$ & Mean & $\begin{array}{l}\text { Standard } \\
\text { deviation }\end{array}$ & \\
\hline $\begin{array}{l}\text { Mastoid } \\
\text { length }\end{array}$ & $29.7 \mathrm{~mm}$ & 3.67 & $24.5 \mathrm{~mm}$ & 3.57 & $\begin{array}{c}<0.0001 \text { (very } \\
\text { significant) }\end{array}$ \\
\hline
\end{tabular}

on North Indian skulls, ${ }^{11}$ the mean mastoid length in male and female skulls was $28.3 \mathrm{~mm}$ and $23.18 \mathrm{~mm}$ respectively. In our present study, the mean mastoid length was $29.7 \mathrm{~mm}$ in male skulls and $24.5 \mathrm{~mm}$ in female skulls which is comparable with other studies conducted worldwide and also suggests a racial variation between different regions of world.

Mastoid length was found to the best sex determinant among mastoid parameters that alone correctly sexed the sample with an accuracy of $66.7 \%{ }^{11}$ while in another craniometric study which included mastoid length as one of the parameters it was found that mastoid length was a significant parameter for sex determination with $\mathrm{p}$ value $<0.05$ and also revealed $90 \%$ accuracy of male crania and $85.29 \%$ accuracy of female crania. ${ }^{12}$ Mastoid process length $(p=0.006)$ was stated to be an independent predictors of sex determination. ${ }^{13}$ In a Stepwise analysis the mastoid length measured as distance between Mastoidale - Porion

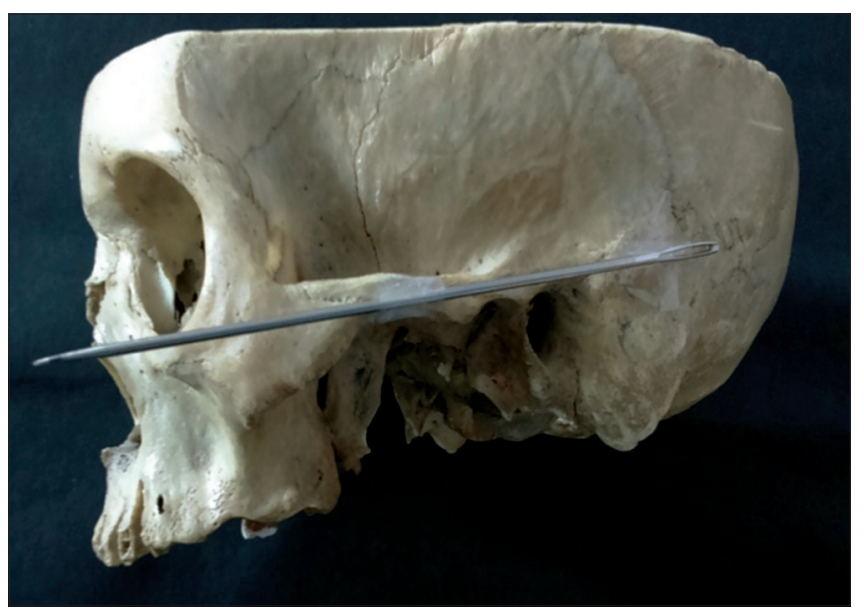

Figure 1: Frankfurt plane: A horizontal plane passing through the upper margin of the external acoustic meatus and the lower margin of the orbital opening

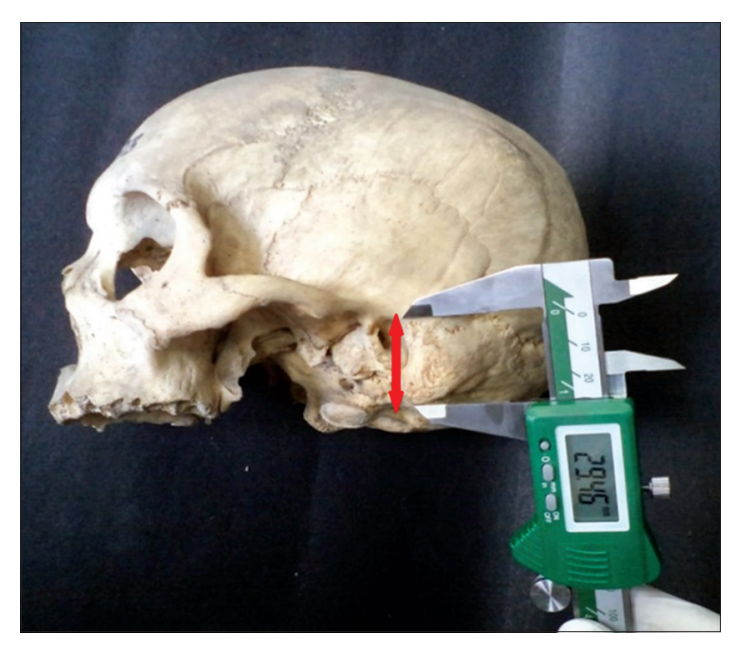

Figure 2: Mastoid Length measured from a point on the Frankfurt plane vertically downwards to the tip of mastoid process (Red arrow) 
was selected as the best discriminant and considered as the best parameter for sexual dimorphism. ${ }^{14}$ The mastoid length was concluded as the best predictor for sex determination among all the variables. ${ }^{15}$

In the present study it was clear that there was variation in the length of the mastoid processes among males and females as demonstrated by statistical analysis. The mean of mastoid length in males was significantly larger than the female mean. Independent t-tests revealed that there was significant difference between males and females, with p-values much less than 0.05 . Therefore the present study validates the use of mastoid length as a reliable metric parameter for the role of mastoid process as a tool for sex determination.

\section{CONCLUSION}

From the present study conducted on 70 dry skulls of known sex and the statistical analysis of $\mathrm{P}$ value which showed to be very significant, it is concluded that mastoid length is a reliable indicator for sexual dimorphism in mastoid process of skulls. Moreover, by comparing our data with other studies conducted worldwide, it can be concluded that mastoid length is higher in males than in females.

\section{ACKNOWLEGEMENT}

We are thankful to the caretaker staff in the museum for their support and help.

\section{REFERENCES}

1. Bilge Y, Kedici PS, Alakoç YD, Ülküer KÜ, and İlkyaz YY. The identification of a dismembered human body: A multidisciplinary approach. Forensic Sci Int 2003; 137(2-3): 141-146.
2. Phenice TW. A newly developed visual method of sexing the os pubis. American Journal of Physical Anthropology 1969; 30: 297-301.

3. Bass WM. Human Osteology: A Laboratory, Field Manual of the Human Skeleton. Special Publications of the Missouri Archaeological Society, Columbia 1971.

4. Whall $\mathrm{J}$ and Henke W. The pars petrosa as diagnostic aid in multivariate biometric sex determination of creamated human remains Z MorpholAnthropol1980, 70: 258-68.

5. Kalmey JK, and Rathbun TA. Sex determination by discriminant function analysis of petrous portion of temporal bone. J Forensic Sci 1996; 41: 865-867.

6. Klaatsch $\mathrm{H}$. The Skull of the Australian Aboriginal. Rep Path Lab Lunacy Dept, N.S.W. Govt., 1908, 1(3): 43-167.

7. Laranch SL, and Macintosh NWG. The craniology of the aborigines of Coastal New South Wales. The Oceania Monographs No. 13. 1966; 43-44.

8. Hoshi H. Sex difference in the shape of the mastoid process in norma occipitalis and its importance to the sex determination of the human skull. Okajima's Folia Anat Japonica 1962; 38: 309-317.

9. Keen JA. Sex differences in skulls. American Journal of Physical Anthropology 1950; 8: 65-79.

10. Giles $E$, and Elliot $O$. Sex determination by discriminant function analysis of crania. American Journal of Physical Anthropology 1963; 21: 53-68.

11. Sumati Patnaik VVG, and Phatak A. Determination of sex from mastoid process by discriminant function analysis. J Anat Soc India 2010; 59(2): 222-228.

12. Deshmukh AG, and Devershi DB. Comparison of cranial sex determination by univariate and multivariate Analysis. Journal of the Anatomical Society 2006; 55(2): 48-51.

13. Vidya CS, Prashantha B, and Gangadhar MR. Anthropometric Predictors for Sexual Dimorphism of Skulls of South Indian Origin International Journal of Scientific and Research Publications, October 2012; 2(10):1-3.

14. Nidugala $H$, Avadhani $R$, and Bhaskar B. Mastoid process - A tool for sex determination, an anatomical study in South Indian skulls. International Journal of Biomedical Research 2013; 04 (02) 106-110.

15. DasGupta A, Banerjee A, Kumar A, Rao SR, and Jose J. Discriminant Function Analysis of Mastoid Measurements in Sex Determination. J Life Sci 2012; 4(1): 1-5.

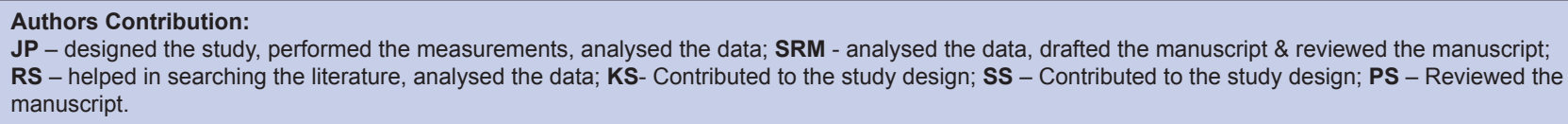

Source of Support: Nil, Conflict of Interest: None declared. 